\title{
Gender discrimination in physics and astronomy: Graduate student experiences of sexism and gender microaggressions
}

\author{
Ramón S. Barthelemy \\ Department of Teacher Education, University of Jyväskylä, 40014 Jyväskylä, Finland \\ Melinda McCormick \\ Department of Sociology, Western Michigan University, Kalamazoo, Michigan 49008, USA \\ Charles Henderson \\ Department of Physics and Mallinson Institute for Science Education, Western Michigan University, \\ Kalamazoo, Michigan 49008, USA \\ (Received 13 January 2015; published 1 August 2016)
}

\begin{abstract}
[This paper is part of the Focused Collection on Gender in Physics.] Sexism occurs when men are believed to be superior to women, and is thought to be one of the reasons for women's underrepresentation in physics and astronomy. The issue of sexism in physics and astronomy has not been thoroughly explored in the physics education literature and there is currently no clear language for discussing sexism in the field. This article seeks to begin a conversation on sexism in physics and astronomy and offer a starting point for language to discuss sexism in research groups and departments. Interviews with 21 women in graduate physics and astronomy programs are analyzed for their individual experiences of sexism. Although a subset of women did not report experiencing sexual discrimination, the majority experienced subtle insults and slights known as microaggressions. Other participants also experienced more traditional hostile sexism in the form of sexual harassment, gender role stereotypes, and overt discouragement. These results indicate the existence of sexism in the current culture of physics and astronomy, as well as the importance departments must put on eliminating it and educating students about sexism and microaggressions.
\end{abstract}

DOI: 10.1103/PhysRevPhysEducRes.12.020119

\section{INTRODUCTION}

Current numbers suggest that women in physics only comprise about $20 \%$ of all undergraduate and graduate students and $14 \%$ of faculty [1-3]. These numbers can vary by subfield $[1,4,5]$, but the overall physics average remains small. This low representation has been the focus of many prior studies. These research efforts have documented gender differences in undergraduate achievement and sought to remedy them [6-8], focused on the work-life balance of women with children $[9,10]$, and studied the experiences of women in physics who hold multiple underrepresented characteristics [11]. The work has primarily emphasized women's experiences as undergraduate students [12-15], with fewer articles tackling the issues of women in graduate programs [16-19].

Though issues of chilly climates, discrimination, and gendered interactions are beginning to be discussed in the literature [20-23], no direct efforts have attempted to demonstrate a language to discuss or identify sexism in

Published by the American Physical Society under the terms of the Creative Commons Attribution 3.0 License. Further distribution of this work must maintain attribution to the author(s) and the published article's title, journal citation, and DOI. physics. This article attempts to start a scholastic dialogue on sexism, or gender discrimination, in physics by documenting the experiences of 21 women in graduate physics and astronomy programs, while also drawing on the broader literature to provide a language with which to discuss these issues.

The following literature review is comprised of three sections. The first describes research on the culture of physics and how women fit, the second describes research on sexism more broadly, and the third describes research on a specific more subtle form of sexism known as microaggressions.

\section{BACKGROUND}

\section{A. The culture of physics}

The natural sciences have largely been absent in direct studies of sexism, with only a few studies looking at these issues in academic medicine [24,25] and field research [26]. Physics offers a productive starting point for this work, not only because of its very low numbers of women, but also due to a uniquely gendered culture which has been described in the literature $[20,21,27,28]$. Physics has also been described as a field that is particularly challenged in observing its own social influences, as argued by Harding [28], and may benefit from a careful dissection: 
Their [physics'] nonsocial subject matter and the paradigmatic status of their methods appear to preclude critical reflection on social influences on their conceptual systems; indeed, prevalent dogma holds that it is the virtue of modern science to make such reflection unnecessary [p. 34].

In addition to the work of philosophers (e.g., Sandra Harding), rigorous social science has also documented the culture of physics and its roots in a masculine design [27]. Traweek [27] lived on site at large high energy laboratories across the world observing physicists, attending research meetings, interviewing faculty, staff, students, and more. In her work she found a community of people who described themselves as having a "culture of no culture." The physicists claimed that social interactions and influences did not pervade into their work and professional decisions. What Traweek [27] found, however, was a community of intense competition and limited resources that were often distributed on the basis of biased decisions and social connections. She found a people who saw dress clothes as being a sign of someone who is not doing enough physics, for they spent too much time on their physical selves. From these examples, amongst the many in the book, it is clear that a culture did exist. There indeed was a community of people that held similar practices and beliefs; it just happened to be unrecognized and unacknowledged.

If social interactions impact who does the science, then the culture and community do have an impact on the knowledge creation. Even in the presence of these glaring subjectivities, Traweek [27] encountered a work force that saw itself as purely objective. They saw physics as the pinnacle of rationality, empty of emotion, and void of human influence. These traits, then, of course, become the hallmarks of what a scientist looks like. In and of themselves, these traits may not be problematic, but in view of the stereotypical descriptions of men and women, such descriptions may imperil women's participation in the field. Keller [29] noted:

[There is a] deeply rooted popular mythology that casts objectivity, reason, and mind as male, and subjectivity, feeling, and nature as female. In this division of emotional and intellectual labor, women have been the guarantors and protectors of the personal, the emotional, the particular, whereas science-the province par excellence of the impersonal, the rational, and the general-has been the preserve of men [29] (pp. 6-7).

If women are seen as contrary to science-particularly the "fundamental" and "objective" field of physics — then they may be immediately seen by the gatekeepers of science and community members as being unfit. Modern research on gender issues in physics has argued this point. Work by Gonsalves [22] showed how women in the field of physics had to ensure that they were not "girly," and not wear things such as high heels and dresses that were seen as being antithetical to the physics community [22]. This means that for women to participate in physics, they must have an awareness of how they present themselves as "woman" in order to be able to assume the characteristics of "physicist." Of course, this means that men, too, must strive to meet these ideal characteristics. The difference is that women are assumed to innately lack these characteristics, while men are assumed to innately hold them.

What impacts do any of these musings have on the actual process of becoming a physicist, and do they really play a role in the overall low representation of women in the field? A way to answer and understand these immediate concerns is to look for empirical evidence that women are, in fact, treated differently in academic physics. If women are actually viewed differently than men, on average, then it may have a significant influence on their careers [30-34].

Although no empirical work has looked specifically at the treatment of women within physics, work has looked at academia and science overall. Research over the last decade has found career-altering biases against women's success in academia ranging from the bachelor's to faculty levels [30-34]. Wenneras and Wold [30] jump started this conversation with their study of postdoctoral fellowship applications to the Swedish Medical Research Council. Although this study is dated, it is important to consider in the context of the studies that followed it. These researchers studied rated parameters of scientific competency, quality of proposed research, and relevance of research, and found that women were ranked lower, on average, in every parameter. The researchers took a look at the scientific competency measure (which was independent of the proposed research) to see if women actually were less competent.

By looking at the applicant's success based on publications in top tier journals and paper citations, they found that women who had the same publication record and academic impact as men were scored lower on scientific competency. In fact, for a woman to be given the same competency score as a man, she had to have three extra publications in a prestigious journal such as Science or Nature [30]. In similar studies, women scientists have also been documented to receive less supportive letters of recommendation when applying to faculty positions than men [33] and have been less likely to be hired into a hypothetical tenure track position when compared to men with identical curriculum vitae [34].

In more recent research, gender biases have also been shown to impact Ph.D. graduates looking for jobs in academia and undergraduates in search of graduate mentors [32]. Hypothetical applicants to a laboratory position were hired more often, deemed as more competent, and suggested to be stronger candidates for mentoring if the hypothetical applicant had a male name rather than a female name [32]. Last, in a study of over 6500 faculty sampled from 259 U.S. doctoral programs, researchers 
found that emails regarding research opportunities were significantly more likely to be ignored if the email came from a student with a name that signaled that they were female or nonwhite [31].

From these studies, it is clear that women are systematically treated differently in academia and science disciplines. An additional notable result is that, in all of these studies, women academics had the same biases against women as did men. So this problem is not just one of representation, but one of cultural impressions and biases. Most of these differences may have been unconscious and unintentional biases perpetrated by the study participants. If such inequities are as widespread as suggested by these articles, then it would not be overreaching to assume that direct mistreatment in the form of sexism may also be present. To begin this conversation, we will start with a definition of sexism and exploration of the ways that it can manifest.

\section{B. Sexism}

To familiarize the reader, we will give an overall discussion of sexism followed by a look at a specific subcategory known as microaggressions. Sex discrimination is discrimination that happens based upon a person's sex or gender, whether perceived or real. Klonoff and Landrine [35] identified certain types of sexist discrimination as "sexist events" (p. 441) [35], which they view as "gender specific negative life events, that is, as gender specific stressors... which happen to women because they are women" (p. 441, emphasis in original). Klonoff and Landrine hypothesized that sexist events have a great impact upon women because "sexist events are inherently demeaning, degrading, and highly personal; they are attacks upon and negative responses to something essential about the self that cannot be changed: being a woman" (p. 442). The data presented by Klonoff and Landrine show that sex discrimination and its experience are "common to almost all women" (p. 447), and these sexist events range from such things as hearing people make sexist or degrading jokes to being treated unfairly due to one's sex in classroom or work situations. For the purposes of this paper, sex discrimination and sexism will be used interchangeably. Although sexism can and does impact women, men, and persons with other gender identities and expressions, this review will focus more broadly on gender discrimination towards self-identified women.

"Modern sexism is characterized by denial of personal bias and prejudice toward women, a general conscious belief in equality of the sexes, but unconscious attitudes that foster nonsupport for programs and legislation helpful to women," according to Sue [36] (p. 168). Modern sexism operates in largely unconscious ways due to false belief systems that are common today, such as the idea that "discrimination against women is a thing of the past" (p. 168).

Sexism can have various consequences for women, affecting their quality of life and well being [35,37-42].
One response found in the research is that women will selfsilence as part of a gendered stereotype around proper female communications in relationships [41]. Therefore, when confronted with sexist behavior, women are more likely to silence themselves versus respond to the sexist behavior directed toward them [41]. This self-silencing in the face of sexist events has been shown to cause additional psychological distress to women [39].

Another study showed that experience of sexist events led to increased symptoms of premenstrual syndrome (PMS), depression, obsessive-compulsive disorder, and general psychiatric and physical symptoms [40]. Berg [37] found a correlation between experiences of everyday sexism and Post-Traumatic Stress Disorder (PTSD), which is a significant mental health diagnosis [37].

Additionally, Dardenne, Dumont, and Bollier [38] found that sexism had a negative impact upon women's performance, in part because women's experience of sexism "created a mindset of preoccupation, self-doubt (including some anxiety), and decreased self-esteem" (p. 775) [38]. These "mental intrusions" caused women to underperform, even at gender-typed activities that should have been skewed in their favor.

Research related directly to the presence of women in STEM fields has found that gender stereotypes around math abilities and proper roles for females have an impact upon women's choices of fields of study, which may also impact their entry into and persistence through these fields [43]. Early in their educational process, girls learn the stereotypical message that boys are better than girls in math, and the girls begin to lose confidence in their abilities [43]. As they mature, they are also exposed to gender expectations that girls are supposed to become wives and mothers and take care of their families and homes. These messages are often perceived as being incompatible with pursuing careers in STEM fields [43].

Further research in STEM fields has also begun to explore sexism. In the field of medicine, gender discrimination against women has been demonstrated at both the student [25] and faculty [24] levels. In the Carr et al. [24] study, about half of all women reported experiencing harassment as compared to only a handful of men. More recently, researchers have explored the harassment experiences of scientists in field science settings [26]. Their survey results indicated that $71 \%$ of women reported experiencing harassment in the field as compared to $41 \%$ of men. They also found that $26 \%$ of women reported assaults against them as compared to only $6 \%$ of men. These experiences primarily occurred while the participants were trainees and were arguably at the most vulnerable points in their careers [26].

Hostile sexism is defined as overt discrimination against women, which may include sexual harassment. An example of hostile sexism would be making sexual advances toward a co-worker or believing that a female 
co-worker should not be in the workplace because of her gender $[44,45]$. Although these overt forms of sexism are problematic and must be dealt with, scholars are also arguing that small day-to-day inequities must be addressed in concert with these larger issues. Daily slights, insults, and unconscious sexist actions are known as microaggressions. Microaggressions are subtle forms of discrimination that are often socially engrained and unconscious. An example of a gender microaggression would be not listening to a woman's idea but then responding to the same idea from a man, or not thinking to initiate a collaborative project with a woman [36]. The following section will explore this more pervasive form of sexism.

\section{Microaggressions}

Sue [36] has identified that although conscious and deliberate acts of sexism have "seemingly decreased," they continue in the form of "subtle and unintentional expressions" of sexism he calls gender microaggressions (p. 11). Sue defines microaggressions as "brief, everyday exchanges that send denigrating messages to certain individuals because of their group membership (e.g., people of color, women, or LGBTs [lesbian, gay, bisexual, transgender])" (p. 24). Although these microaggressions are often overlooked or forgiven as unintentional, gender microaggressions have been found to impair performance in multiple settings by negatively affecting women's quality of life [36]. Gender microaggressions act upon women in several ways, by reiterating the social view that men are more valued than women, by reinforcing traditional stereotypes about proper gender roles, and by contributing to violence toward women by objectifying and sexualizing them [36].

Sue and Capodilupo [46] have identified several microaggressive themes which have emerged from research: (a) sexual objectification; (b) second-class citizenship; (c) use of sexist language; (d) assumption of inferiority; (e) restrictive gender roles; (f) denial of the reality of sexism; (g) invisibility; and (h) sexist humor jokes (p. 70) (Table I). These microaggressive messages can be delivered verbally through direct or indirect comments, nonverbally or behaviorally through body language or physical actions, and environmentally through physical surroundings. These microaggressive messages are often "delivered through educational texts, mass media, institutional norms, and cultural scripts that are not necessarily overtly sexist, but communicate hidden messages that may be internalized by both perpetrator and victim" (p. 164) [36].

Furthermore, due to the subtlety and often ambiguous nature of microaggressions, the perceived targets often question themselves about whether or not the incident was motivated by gender bias. The messages communicated by microaggressions are subtle but powerful, and attempts to
TABLE I. Gendered experiences.

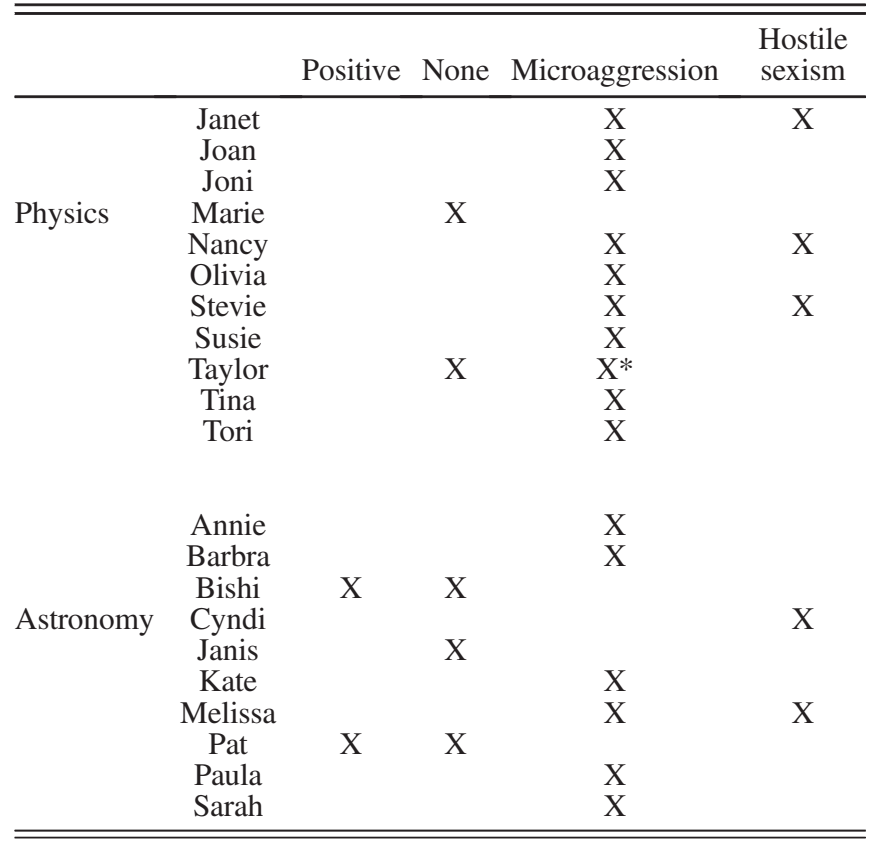

discuss them can be met with heated disavowals, in part because the harm from microaggressions is perceived as "minimal" by the often unconscious perpetrators. This creates psychological dilemmas for those attempting to respond to microaggressions, in part because they are unsure of the motives of the person who committed the microaggression. This uncertainty around microaggressions leads to a Catch-22, as the victims are also uncertain how to respond to the perceived microaggression, or feel that the response is already too late. Additionally, there is some fear that the response will not have an impact, or may have an unintended impact in the form of repercussions. Finally, the victim of a microaggression may "deny experiential realityengaging in self-deception by believing it did not happen" [36] (p. 56).

As compared to hostile sexism, microaggressions are particularly difficult to isolate, confront, and resolve. Thus, it is important to pursue research to explore these kinds of experiences of women in physics and astronomy and build constructive ways to prevent and address them. The study below explores the gendered experiences of women in both graduate physics and astronomy.

\section{METHODOLOGY}

\section{A. Research question}

The research question used to guide this work was "How can we understand the gendered experiences described by these women through the frameworks of microaggressions and hostile sexism?" The experiences that were categorized from these women were both from a specific interview question about their gendered experiences and from other 
personal stories described throughout the entirety of the interview, which included or referenced gender.

\section{B. Theoretical framework}

The theoretical framework used in this study is Feminist Standpoint Theory (FST) [47,48]. FST stems from the Marxist philosophical belief that those in power have a significantly different viewpoint of social structures and realities than those not in power [48]. Consequently, seekers of knowledge should focus on creating understanding from the perspective of those who are oppressed, and thus be able to see things from the perspective of a person within a system and a person who is not advantaged by the system. FST uses this foundation to value the perspective of women's lives and assumes fidelity and truth from their perspective and experiences. FST was chosen to view women's lives as the central point for the discovery of knowledge about the process of an education in graduate physics and astronomy

This is an important foundation for both data collection and analysis. First, it demands that data are collected and presented from the viewpoint of women's lives. Great caution has to be taken in the process of conducting interviews to ensure participants are not led to responses from questioning cues and have the autonomy to guide the conversation as they see fit and bring up experiences and stories important to them. The use of FST in this study guided the researchers to design open-ended prompts and conduct all interviews as participant-guided conversations.

Second, FST helped the analysis by making the first and second authors continually ensure that the results were grounded in participant experiences and told through their voices (i.e., direct quotes). In the process of data analysis, the first and second authors used their own standpoints as a male physics education researcher and a female in the field of sociology. Together they brought different lived perspectives that helped inform their analysis. Last, since FST argues that women's experiences must be seen as their truth, the researchers did not question women's experiences or interpret them in ways not presented by the women themselves.

\section{Data collection and analysis}

In-depth semi-structured interviews were conducted by the first author and were used to collect data. The interviews were collaborative in nature and conversational in form. They centered around prompts such as, "Tell me about the pathway that lead you to physics (astronomy)." Further probing questions were used, such as, "Tell me more about your relationship with the professors in your classroom." This publication will focus on participant responses to one prompt: "How do you feel your experience has been different because you are a woman?" This question was designed to open up a conversation about their gendered experiences without leading them to talk about either positive or negative experiences. Participants, though, often discussed gendered experiences in other parts of the interviews. For example, some women, when discussing their experiences with other students, would reference gender in terms of their classmates, or interactions with their classmates or peers in terms of study groups. These other mentions of gender were part of a natural flow of discussion about their experiences within the educational setting and were not prompted by the research question. Because of the specific references to gender, these experiences were also included in the analysis.

Data analysis began as soon as the first interview was conducted. Interviews were read and reread while constantly comparing them to one another [49]. The first and second authors would meet weekly after reviewing one participant's interview and coding them independently. Codes were used to describe specific concrete experiences such as Research Experience as an Undergraduate or Mentoring from Postdoc. The first and second authors would discuss their coding, what they found, and how the codes could be combined to form greater meaning, or rather, themes. These themes were discussed between the first and second authors and were used to build an understanding of how these participants navigated their pathways through graduate programs.

The consensus view of coding would then be inputted into a digital software package to create an archived record. After this process, the coding and themes would be presented and discussed with the third author who advised in the analysis process. In all, 169 codes were applied 841 times and resulted in 17 themes. In this paper we will discuss the theme of Gendered Experiences. This theme was comprised of many codes, such as Being ignored by other students and Restricted from laboratory equipment, and consists of answers to the particular question related to gendered experiences and any other remarks by the participants that referred to gendered experiences.

When conducting preliminary analysis on the gendered experiences theme, we noted that some participants shared stories of incidents of hostile sexism. Many other incidents shared by participants could be classified as microaggressions. As such, we chose to use the two frameworks to explain the findings. In order to apply these frameworks, both authors read and reread the gendered experiences data and coded the incidents as either microaggressions or hostile sexism. In cases of disagreement, the authors would continue a discussion until consensus was achieved. At times, this included coding some experiences under more than one category, which will be further addressed below.

\section{Researchers}

The theoretical framework choice for this work, FST, also impacts the personal reflections of the researchers on their research process. Each one of us came to this work with his or her own standpoint that had to be accounted for 
in the research process. Author one conducted all of the interviews and did not share a gender identity with the participants. When the first author recruited participants, he made the intentions of the research clear and included a link to his website so each potential participant could know who he was and be aware of his overall research goals. Each participant also had the opportunity to ask questions before and after the interviews about the work, the author's goals, and how their anonymous stories would be used.

In line with FST, the first author made sure to frame all questions about the participant's lives without guiding them to specific answers. Although he did not share a gender identity with the participants, he did experience undergraduate and graduate physics programs as an underrepresented person in the field, which gave him some insight into women's unique experiences. However, he is not a woman and cannot fully understand their standpoint. Consequently, the second author was invited into the research process. She came to the research process with the perspective of a single-mother graduate student in a sociology program. She also is a licensed social worker and holds a degree in psychology. Her standpoint allowed her to reflect on the experiences of women and mothers in higher education as well as bring a unique academic perspective.

Between the first and second authors, they could look at the research data and check each other's bias. For example, the second author could better inform the first author about challenges met by women and the first author could better inform the second author about the challenges specific to graduate physics and astronomy programs. The third author brought a different standpoint to this process, acting as an expert adviser on research in physics education to ensure strength of research and determine how the project added to the physics education research community.

\section{Participants and recruitment}

Participants in this study met three criteria: (i) gender identify as a woman; (ii) were in pursuit of a Ph.D. in physics, astronomy, or astrophysics; and (iii) passed their qualifying examination or equivalent. Students were recruited from major research universities that are highly ranked and respected in the physics and astronomy communities. Recruitment letters were sent out to persons identified from online graduate student lists, by contacting research group leaders, and by sending invitations to women in physics and astronomy groups. Additionally, at least 57 individuals were sent a recruitment email as well as the email list invitations. In total, 21 interviews with women in their later stages of graduate education were conducted. The participants were predominantly White and came from homes with mostly educated parents living middle or upper middle class lives. Further details about participants will not be revealed in order to protect their anonymity. All names presented in this study are pseudonyms.

\section{RESULTS}

The results section will be divided into three main sections based on the participants' experiences with sexism or gender microaggressions: (i) those who reported no gendered experiences; (ii) those who reported experiencing what can best be described as microaggressions; and (iii) those who reported experiences which were overtly hostile sexism. Table I lists all the participants by field and indicates the form of sexism they reported. Participants could be listed in multiple categories, based upon their reported experiences. For example, in Table I, Taylor is listed under both "none" and "microaggression."

This is because in Taylor's initial response, she reported not having any gendered experiences. However, in other parts of her narrative, she reported an incident that is coded as a microaggression (see below).

\section{A. No gendered experiences}

In our data, some women $(5 / 21)$ reported they had not experienced differential treatment due to their gender. When asked about their personal gendered experiences, some participants reported never having them, and in the case of two participants, being a woman was seen as advantageous, which we noted as "positive" in Table I. Bishi, who was in astronomy, liked that her voice was different from her male colleagues' on the phone; she felt it made her stand out. Pat (also in astronomy) reported that being a woman gave her access to resources she may have not had otherwise:

...being a woman in physics/astro has actually helped me...I have actually benefited from programs aimed at reaching out to women in science...-Pat (Astronomy)

By participating in a women-in-science program, Pat had the opportunity to do undergraduate research and travel to remote telescope locations to collect data. Another participant, Marie (physics) described never having been deterred by men in physics:

I grew up thinking of course women can do whatever men can do... and then I realized oh, that's because I already have [a] role model.-Marie (physics)

Marie's mother was a single parent who held an advanced STEM degree. Marie saw her mother as an example that women can succeed at anything. She alluded to the fact that having such a role model may have been why she was not impacted by gender throughout her education in physics.

Taylor (physics) added nuance to the conversation around gendered experiences, as seen in Table I. Although Taylor felt that she had not been treated differently because of her gender, she did share that she believed such treatment happened: 
I think most people interact with you a little differently when you are a woman, whether they mean to or notthey just make different assumptions about your abilities and interests... Has anyone ever asked you if you know how to use a wrench?-Taylor (physics)

Taylor's view of gendered experiences was complicated. From Taylor's standpoint, she did not feel she was treated differently, even though she stated that she believes that differential treatment happens. She also shared, however, that she had some educational experience with such gendered treatment in her undergraduate experience, when someone asked her about using a wrench. The comment about the wrench could be coded as two different microaggressions: "assumption of inferiority," which refers to women's inherent inability to perform tasks, or "restrictive gender roles," which assumes that women's roles preclude the use of tools.

\section{B. Microaggressions}

Microaggressions were present in many $(16 / 21)$ of the narratives of the participants. Following the work of Sue et al. [45] on gender microaggresions, the data below have been organized into the same subthemes. In Table II the subtheme is followed by a definition and an example from the participants in this study. Microaggressions in this analysis include both direct incidents and cultural expectations that act as microaggressions, such as the feeling of having to dress in a masculine manner to fit into the culture of physics. Many of these microaggressions could be categorized in multiple subthemes, as we saw above with the example of Taylor. Table II defines the subthemes and gives an example from our data which most closely matches the subtheme.

As a way of elucidating how the gendered experiences of our participants fit within the framework of microaggressions, we present each area, along with examples which we felt fit the subthemes below.

\section{Sexual objectification}

The first area of gender microaggressions identified by Sue [36] is sexual objectification. Three of our participants addressed this directly, and all of these examples focus on the women's presentation of themselves and their awareness of being viewed as objects:

I regularly wonder about appropriate work attire, since being good-looking as well as female is often associated

TABLE II. Gendered subthemes for microaggressions $N=16 / 21$ reporting.

\begin{tabular}{|c|c|c|}
\hline Subtheme & Definition & Example from participant data \\
\hline Sexual objectification & $\begin{array}{l}\text { Reducing women to their physical appearance } \\
\text { or assuming their bodies should be controlled } \\
\text { and commodified by men }\end{array}$ & $\begin{array}{l}\text { "[I] worry that men may want to collaborate with } \\
\text { me only because they are sexually interested, not } \\
\text { because they respect my intellect or teaching } \\
\text { style." Joan, physics }\end{array}$ \\
\hline Second-class citizenship & $\begin{array}{l}\text { Treated as a lesser person or group; Belief that } \\
\text { women should not have same access to } \\
\text { resources and opportunities as men }\end{array}$ & $\begin{array}{l}\text { Yes, um, it was hard as an undergrad, um, to be the } \\
\text { only girl in the classroom because I felt so } \\
\text { conspicuous... that might have been part of why } \\
\text { I was constantly questioning whether I belonged } \\
\text { there. Paula, astronomy }\end{array}$ \\
\hline Sexist language & Language that infers superiority of men & "lady physics" Tori, physics \\
\hline Assumption of inferiority & $\begin{array}{l}\text { Assumption of women's inherent inability to do } \\
\text { certain tasks }\end{array}$ & $\begin{array}{l}\text { "Like what is that... protective feeling that men } \\
\text { have of women in the workforce? They don't } \\
\text { expect as much from them, or like, give them } \\
\text { easier tasks." Olivia, physics }\end{array}$ \\
\hline Restrictive gender roles & Belief that women must play certain roles & $\begin{array}{l}\text { "My place in the lab can at times feel } \\
\text { uncomfortable.... I am basically the lab } \\
\text { secretary." Janet, physics }\end{array}$ \\
\hline Denial of reality of sexism & Not believing that sexism exists & $\begin{array}{l}\text { "I felt they got a little confrontational, like why do } \\
\text { you need this women in physics group?" Tori, } \\
\text { physics }\end{array}$ \\
\hline Invisibility & $\begin{array}{l}\text { Not including or recognizing women in the } \\
\text { workplace or world }\end{array}$ & $\begin{array}{l}\text { "It almost feels like you don't, belong, like you're } \\
\text { not um, like you're an accessory to the } \\
\text { conversation or you're not like one of the guys." } \\
\text { Barbra, astronomy }\end{array}$ \\
\hline Sexist jokes & $\begin{array}{l}\text { Crude jokes about women, rape, domestic } \\
\text { violence }\end{array}$ & $\begin{array}{l}\text { "[An] international student asks why women in the } \\
\text { US are called 'chicks.' People begin to give him } \\
\text { direct answers, but he interrupts and says, 'I } \\
\text { think it is because you like chickens for their } \\
\text { legs. Not their brains.", Joan, physics }\end{array}$ \\
\hline
\end{tabular}


with not being intelligent. I therefore choose my wardrobe so that I do not look "overly attractive," since I want to be taken seriously by my peers.-Joan (physics)

Joan also discusses how this impacts her confidence:

... my worry that men may want to collaborate with me only because they are sexually interested, not because they respect my intellect or teaching style, which means that my confidence is lower than it would be if I didn't have this worry.-Joan (physics)

Kate discusses a similar experience in which she is concerned with being taken seriously and takes measures to vary her appearance to appear more masculine or professional:

I don't really need glasses but I have glasses and I'll like put them on and like, pull my hair back if I wanna be taken more seriously if I'm giving a talk, if I want to be more professional.-Kate (astronomy)

Barbra, on the other hand, feels like her gender and youth contribute to the number of people who attend her poster presentations:

At conferences I feel like I get a lot of attention at my posters because, I don't know, I feel like people want to come talk to the friendly young girl and maybe they don't want to talk to some guy.-Barbra (astronomy)

These women's stories show an awareness of their gendered performances and how those can impact them being viewed as professionals in the field. Some of these quotations directly refer to the possibility of sexual objectification, while others allude to it, such as Kate's example. One of the descriptors used by Sue [36] in describing sexual objectification includes the idea that a female's body or appearance is for "men's enjoyment or pleasure" (p. 34). These women's concerns seem to be related to how they feel they need to manage their presentation of themselves in order to be perceived as serious and intelligent and to be received or perceived as peers.

\section{Second-class citizenship}

In our analysis, 10 interviewees reported experiences that we coded under the microaggression Second-class Citizenship, which infers that women are less as a group, or that they should not have the same access to resources as men. Stevie mentioned the feeling of "missing out on something important" because of her gender:

You know, I guess it's different in this field just because there are so many men. Sometimes you wonder if you are missing out on something important just because you are a woman. And I can tell sometimes that the grad students (the general population, not the ones that I work with directly), interact with me differently because I am a woman.-Stevie (physics)

Olivia talks of having a "different experience" than men in the field. "Like what is that, you know like that protective feeling that men have of women in the workforce? They don't expect as much from them, or like, give them easier tasks." This example clearly belongs in the category of second-class citizenship, as the underlying message is that women are not equal to the tasks required of physicists.

Joan describes "needing to constantly prove myself." This example addresses the pressures of being underrepresented in the field and having to constantly prove her own worth, since, as a female, she is assumed to be a lesser person in the field.

\section{The use of sexist language}

The Use of Sexist Language was the least reported microaggression in our data, with only two participants mentioning examples. Tori gives a particularly strong example of this, when she shares a comment she has heard about her participation in "lady physics," a phrase used to describe her research area. This statement infers that there are two fields of physics — physics and "lady physics." This is sexist language, because it infers the superiority of men over women, and infers that the "lady physics" are less than physics in general.

Joan shared an example of the language she heard from a classmate, which can be categorized both as sexist language ("chicks") and as a sexist joke ("you like chickens for their legs. Not their brains"):

[An] international student asks why women in the US are called 'chicks.' People begin to give him direct answers, but he interrupts and says, "I think it is because you like chickens for their legs. Not their brains." Everyone laughs (some with some trepidation) and looks at me to see my reaction. ... [I] felt quite singled out and embarrassed, in addition to feeling like I was somehow expected to defend myself, in addition to brushing it off.-Joan (physics)

Joan's example also includes her perceptions of the event and how it made her feel. The event singles her out as female, which in this case is denoted as inferior, and also comes with pressure for her to respond. This is a good example of how microaggressions work on those at whom they are aimed. She is demeaned and at the same time is expected to respond by either defending herself or agreeing that it was not insulting.

\section{Assumption of inferiority}

Ten of our participants shared about the microaggression Assumption of Inferiority. The following excerpts show 
different ways in which this message was conveyed to the women. Tori shares that "in this group, I gotta, you know, prove that I can hang in and make it here." Janet shared ways in which the message of inferiority was conveyed to her:

I feel, especially recently, that I am not listened to within my group. This is mostly by my peers (my adviser tends to do a better job). A lot of my suggestions are brushed off. If, later, they turned out to be correct, people forget that I ever made them. ... [In] another situation I told the grad student under me that he should consider a certain factor in trying to make sense of his data. He said no and ignored me. When the other grad student/post doc suggested it, he was open to it right away.-Janet (physics)

Janet's input was ignored. The underlying message of this is that her input is not valuable due to her status as a female. This example, however, could also easily be classified as invisibility, since she feels that she is ignored and unrecognized. Additionally, many examples of this category also overlap with those in the category Secondclass Citizenship. The examples given in these two categories were often coded in both, due to their similarity, as assumptions of inferiority and second-class citizenship often go together and may be difficult to disentangle. This is a weakness of using Sue's [36] microaggression framework in this way, and this will be addressed below.

\section{Restrictive gender roles}

Twelve of our participants reported restrictive gender role microaggressions, but Joan's example sums them up quite well:

It is exhausting and I feel that I must refute every idiotic claim produced to avoid being challenged or disrespected for my gender! Exact claims include "Women are worse at spatial cognition than men." "Men are obviously stronger than women."... there are many more.-Joan (physics)

Joan perceives these comments as sexist, and at the same time, they also uphold societal beliefs about gender roles. Stevie discussed three different male colleagues who "didn't think women should be in science," one of whom refused to talk with her. Melissa shared about a male colleague who told her that "women can't do science because they should be ... taking care of babies." The message from these examples is that women do not belong in the field, as their presence there is in direct conflict with their gender roles as females.

\section{Denial of the reality of sexism}

Only two of our participants reported examples of this microaggression. Tori experienced some hostility from male peers regarding her desire to participate in a women in physics group.

"I felt they got a little confrontational, like why do you need this woman in physics group?"-Tori (physics)

Joan also shared comments that she had heard from peers:

"If you didn't get a scholarship, you didn't work hard enough and therefore don't deserve to get extra time to study for quals." (That was a personally directed challenge). "Maybe the reason women get paid less than men is that they don't work as hard." "There are many cases of 'discrimination' that are total bullshit."

\section{Invisibility}

Nine participants reported this microaggression, and it has been alluded to in several examples above, where participants spoke about not being heard or listened to by their peers due to their gender. Barbra's description, below, sums up much of what the participants discussed in their narratives:

How do you make your voice heard is a little bit tough. The whole program feels like a(n) old boys club sometimes. I mean, I go to conference dinners or um colloquium dinners and I'll be the only woman most of the time and, (pause) yeah. Uh, it, it almost feels like you don't, belong, like you're not um, like you're an accessory to the conversation or you're not like one of the guys.-Barbra (astronomy)

\section{Sexist jokes}

This microaggression was present in only two narratives. Joan, however, shared a very blatant example:

...there have been, uh, situations with a past group member that made some very inappropriate comments and jokes... a joke about date rape and a joke about domestic violence.... it was a problem. I talked to my advisor about it...nothing was ever done about it.-Joan (physics)

The comment and the response, or lack of response, from the advisor, were problematic for this participant. The fact that such comments can be made without consequence says something about the environment in which the "joke" can be made. For women who have experienced domestic violence or rape, such talk may lead the women to feel unsafe in the environment, and a lack of response to a woman's reports of such talk will only increase that feeling.

As discussed earlier in this section, there were experiences shared by our participants could be placed in multiple categories. In his own definition of "assumption of inferiority," Sue [36] discusses women feeling invisible, 
unimportant, and less informed than their male colleagues (p. 172). Likewise, he includes telling sexist jokes under the category of sexual objectification (p. 170). Clearly, there is much overlap between these descriptive categories, which is a limitation of the use of this framework. However, this lack of distinct divisions does not warrant giving up the framework, since it has great power in terms of explaining how small, often unconscious, behaviors can work to convey sexist messages to women. Instead, we may posit that sexist messages are often very complex and may contain multiple messages for women.

Overall, this analysis found that gendered experiences which could be classified as microaggressions were reported by a large proportion of the $(16 / 21)$ women in this study (76\%). Furthermore, it was common for women to report experiencing many different types of microaggressions, versus only reporting singular incidents. This high reporting of microaggressions seems especially problematic from the perspective of reducing sexism in physics and astronomy departments.

\section{Hostile sexism}

For five of the participants (Janet, Nancy, and Stevie in physics and Melissa and Cyndi in astronomy), hostile sexism was an unfortunate reality in their educational pathways. Their experiences moved well beyond microaggressions, because they were directed towards them as gendered individuals and could have had devastating consequences for their careers. In the cases of Nancy and Stevie their careers did continue, but were significantly altered. Cyndi encountered hostile sexism the earliest in her career, while still in high school:

Many of the boys in the [AP physics] class expressed interest in engineering. When it got around to me, I responded that I wanted to major in physics. The teacher raised an eyebrow and said "Oh, so you're going to be a waitress"...-Cyndi (astronomy)

For Cyndi, this overt discouragement did not deter her; she was already enrolled in community college and had planned to pursue her education in physics (and eventually astronomy) further.

The rest of the participants all experienced hostile sexism as graduate students in pursuit of their research. Janet had to endure sexist jokes about women, and Melissa and Stevie struggled with graduate students who did not believe women had a place in the lab. Melissa explained:

I was observing with someone ... and [he was] just going on about why women can't do science because they should be...taking care of babies and [I] should be thinking about having babies soon... It was...frustrating. Like I literally, like, couldn't even deal with this person... I just feel so disrespected...-Melissa (astronomy)
Melissa's feeling of frustration lead to her silence. She only told one fellow student about this experience. Against her wishes, this student reported the matter and resolution was found at the hands of a female professor. Melissa was scheduled away from the student making these comments and he was reprimanded. Stevie, however, found no such support when she discussed the sexism she experienced with her advisor.

Stevie's advisor was largely absent and the lab was student-run. When Stevie attempted to work on experiments, a male colleague informed her that a woman's place was not in the lab, it was at home. He made this point clear to Stevie and prevented her progress:

He's [another graduate student] not too fond of women, in general. And he made a point to make sure I understood that ... if I asked for something like, I want time to do experiment stuff.... He wouldn't give it to me.-Stevie (physics)

Stevie sought support from her research advisor and the graduate student advisor, but she found none. She eventually switched labs against both of her advisors' advice and found a research advisor who did not do research in her areas of interest, but who had a track record of supporting women advisees.

The last participant to be discussed in this section is Nancy. Nancy's experience stands above all the other participants' because of the severity of the sexism she experienced and the silence she was met with from the physics faculty when she sought assistance. Nancy was assigned a teaching assistant (TA) in her graduate advanced physics course who became infatuated with her. She told him she was not interested, but he did not listen. He eventually became aggressive with her and did not relent in his attraction. Eventually he acted out in violence toward her:

He was obsessive, violent towards objects, I just wanted to get away from him...he punched holes in the wall because I happened to be in the building...He was angry at me...he didn't respond to 'leave me alone'...-Nancy (physics)

Nancy explained that she was only confident in reporting his behavior because she was a top student. Although the faculty said they would remove him as her TA, he was actually placed again as her TA the following semester and subsequently removed when she voiced her concerns again. Her harasser was never reprimanded for his actions and was merely sent to counseling. Nancy no longer felt safe in her department and physically left the university to finish her dissertation remotely at a large national laboratory in another country.

In the cases of all of these women, four attempted to find resolution by reporting their experiences to superiors. However, with only one exception (Melissa), these reports 
were met with deaf ears. Janet, Stevie, and Nancy had to find their own ways to survive and avoid their harassers. Although Janet just continued in her lab avoiding her male colleagues as best she could, Nancy and Stevie relocated to different labs to extract themselves from the situations in which they felt unsafe due to hostile sexism.

\section{DISCUSSION}

The results section demonstrated the negative gendered experiences of many women in both physics and astronomy, and answered the guiding research question by showing that these experiences could be understood using the frameworks of microaggressions and hostile sexism. Interestingly, no differences between the two fields were visible. Although astronomy has a much larger representation of women compared to physics, the same gendered experiences were described in both fields. What is clear from the data, however, is that the overall environment within physics and astronomy pervasively and subtly impacts women, at least for the majority of participants. This environment seems unsurprising when considering the previously described culture of physics, which has been found to alienate and discourage women's participation [27,28,50], as they are not seen as being inherently part of the field. No single aspect of these women's experiences affected their persistence or caused them to leave the field. Rather, an accumulation of disadvantage from many small incidents led to the departure of some of the participants from their fields of study. Unfortunately, many of these incidents were unacknowledged by the perpetrators and community, and were ignored when brought to the attention of administration. Lastly, it is also important to mention the minority of participants who reported no gender microaggressions or hostile sexism. In terms of creating a female-friendly environment [12], this is the goal for all students in these fields.

\section{A. Environment and culture of physics}

The experiences described by these women combine to illustrate a physical and cultural environment that is discouraging of women's participation in physics and astronomy. The microaggressions and hostile sexism described by these participants worked to impede their participation in research, alienate their very presence in the fields, and discourage their persistence. The microggressions and hostile sexism resulted in ignoring these women's ideas, conveying a message of women as objects, and restricting access to laboratory equipment. These interactions fundamentally changed the relationship these women had to their fields. These women were not able to interact with physics or astronomy as full participants, but as people mediated by the role expectations and restrictions placed on them.
Within the environment of physics these women also struggled with the actual spaces in which they did their work. For Janet, in particular, her relationship with the physical space in which to conduct physics was mediated. The space, to her, was not one of just science. It was one where she had to clean, organize, and do tasks the men in her group were never assigned. For Melissa and Stevie this was also true. When they attempted to conduct research at a telescope and national lab, respectively, male graduate students attempted to block their access to equipment and data. For Nancy, her physical safety was in jeopardy whenever she entered the physics building. The literal physical space of physics and astronomy for these women was changed because of the actions of men. The physical space became one of nonscience-related work, confrontation, and bodily danger.

The physical space also manifested disadvantages for these women's psychic interactions. When these women wanted to share ideas, participate fully in the research process or just be present during discussions, their actions were challenged. These women were not heard in the research groups when voicing thoughts, endured sexist comments and jokes, and, in some cases, were reminded of the gender roles they should hold. Additionally, at times they were explicitly discouraged from pursuing their goals in science. In Whitten et al.'s [13] article on supporting women in physics, one of their major recommendations was that the space be perceived as safe for the women. In this way, the departments in which many of these women were involved failed to meet the standard.

This environment and culture these women experienced were indicative of the environments and cultures described previously $[22,27,28]$. The field of physics was described as a masculine domain in which the presence of women was seen as innately antithetical to the field. This resulted in challenges to women's participation in the departments. Women's presence and potential contributions were seen as fraudulent and were met with opposition through experiences of microaggressions and hostile sexism in the data provided by our participants, which leads us to wonder if the culture of physics has indeed altered since the earlier cultural studies $[27,28]$.

Clearly, the men (and in some cases women) may have not been aware of their own treatment of the participants in some cases, such as when their ideas were not heard or their research choices were questioned. On the other hand, there were examples that were clearly conscious, such as physically assaulting property when the participant was around or directly telling her she shouldn't be pursuing physics or astronomy but instead be at home having children. Although these examples were not discussed by many participants $(5 / 21)$, it is problematic that almost a quarter of our participants reported incidents of hostile sexism within their departments, especially considering that the nature of the gender prompt in the interview was very open-ended and that the participants were talking to a 
male interviewer. The majority of the participants reported more subtle forms of sexism, and this is also concerning. These experiences may not have made them quit or leave their programs outright, but over time these experiences can create an accumulation of disadvantage.

\section{B. Accumulation of disadvantage}

"Each example that I have discussed is a small thing. One might be tempted to dismiss concern about such imbalances as making a mountain out of a molehill. But mountains are molehills, piled one on top of another over time" (pg. 210) [51].

A single experience of a microaggression, and even in some cases hostile sexism, most likely will not stop women from pursuing their goals in physics and astronomy. It is the accumulation of all of these small cuts that create a large wound, which endangers a woman's success in physics and astronomy. Over time, if women's ideas are constantly unheard, they aren't invited to informal networking events, aren't considered for collaborations, etc., their careers will be impacted. Just a few less publications or grants can cost an individual a promotion or access to continue their work. Continual discouragement through subtle messaging and exclusion may also make women set their goals lower, which, over time, results in overall less achievement.

Additionally, previous research has shown that the incremental effects of continuing bias against women can lead to symptoms of post-traumatic stress disorder [37] and may lead them to be increasingly vulnerable to future trauma. Martell et al. [52] demonstrated that by adding small amounts of bias (as measured by differences in performance ratings) against women they could change a pool of people who were equally men and women to be $65 \%$ men by the end of an eight-tiered computer simulation [52]. Small biases matter, and it may be the accumulation of small events that creates the discrepancies seen in physics and astronomy, and not any one cause. The first step in combating this is recognizing that modern day sexism does exist and often differs from historical examples of discrimination.

\section{Limitations}

It is important to recognize the overall limitations present in this study. The limited sample size and breadth of the data collection is an immediate constraint. However, the extent to which women experienced microaggressions suggests there may be validity in drawing conclusions from their experiences. An unavoidable limitation, however, is that the correlation to physics or society in general cannot be untangled. Further data are needed from other disciplines to argue for or against the roles of physics and astronomy in the manifestation of these experiences. Last, the voices of these participants are largely from upper-class privileged white women. They do not represent the diversity of women who live in the United States nor those who may leave the field of physics or astronomy before passing graduate-level exams. Further research should seek to diversify the participants when possible. This may include women of color, trans women, women with disabilities, and lesbians.

\section{CONCLUSION}

The overall goal of this article was to share the gendered experiences of successful women in pursuit of their educations in physics or astronomy, while also demonstrating a language for physicists and astronomers to discuss sexism in their departments. Although examples of hostile sexism in the form of sexual harassment and gendered stereotypes exist in this data set, the majority of the reported experiences were subtle, difficult to label, and may have been unconscious on behalf of the perpetrators. When considering sexism in one's own research group or department, it is important to consider ways in which to mitigate microaggressions and the differential treatment of women by both men and women.

One way to combat microaggressions is through awareness and education. Organizations need to provide training regarding gender microaggressions and sexual harassment [45]. Faculty, in particular, need to be trained to be aware of how they may inadvertently treat women differently and be advised to ensure equal treatment. This can be done by making sure tasks in the lab are assigned fairly, every student has equal access to equipment and can share their ideas at ingroup meetings and during experiments, and that faculty are equally available to all students [53]. Small acts such as these may help address inadvertent gender bias which affects female students and thus allow fuller participation [45].

Beyond education on microaggressions, departments need to have a tough and vocal stance regarding their refusal to tolerate a hostile work environment toward women [45]. Some ways to meet this goal include asking students and faculty to attend annual colloquia on sexual harassment and be made aware of both the consequences and reporting mechanisms in place within the university. Students, undergraduate and graduate alike, need to be strongly encouraged to report incidents, and the department needs to have policies and procedures in place for follow up. Further, Sue [45] recommends accountability for maintaining a bias-free environment as a part of leadership positions. A no-tolerance policy for a hostile work environment would mean that perpetrators of hostile harassment should be dealt with severely, involving police when necessary, such as when it involves physical assault, verbal harassment, and stalking.

Through careful consideration of the kinds of sexism existent in the physics and astronomy communities and targeting them for education of community members, it may be possible to create a culture hospitable to all persons. Such an environment can only benefit the fields by ensuring the production of scientists engaged in top quality work. 
[1] AIP, American Institute of Physics Statistical Research Center (2014), https://www.aip.org/sites/default/files/ statistics/undergrad/bachdegrees-p-14.pdf.

[2] P. Mulvey and S. Nicholson, Trends in Physics Ph.D.s (American Institute of Physics, College Park, MD, 2014).

[3] R. Ivie et al., Women Among Physics and Astronomy Faculty (American Institute of Physics, College Park, MD, 2013).

[4] R. S. Barthelemy, C. Henderson, and M. L. Grunert, How did they get here?: Pathways in physics education research, Phys. Rev. ST Phys. Educ. Res. 9, 020107 (2013).

[5] R. S. Barthelemy, B. Van Dusen, and C. Henderson, Physics education research: A research subfield of physics with gender parity, J. Women Minorities Sci. Eng. (to be published).

[6] M. Lorenzo, C. H. Crouch, and E. Mazur, Reducing the gender gap in the physics classroom, Am. J. Phys. 74, 118 (2006).

[7] L. E. Kost-Smith, S. J. Pollock, and N. D. Finkelstein, Gender disparities in second-semester college physics: The incremental effects of a "smog of bias", Phys. Rev. ST Phys. Educ. Res. 6, 020112 (2010).

[8] L. E. Kost-Smith et al., Replicating a self-affirmation intervention to address gender differences: Successes and challenges, in Proceedings of the Physics Education Research Conference, edited by N.S. Rebello, P. V. Engelhardt, and C. Singh (American Institute of Physics, Omaha, NE, 2011).

[9] R. Ivie and C. Tesfaye, Women in physics: A tale of limits, Phys. Today 65, No. 2, 47 (2012).

[10] M. A. Mason and E. M. Ekman, Mothers on the Fast Track: How a New Generation Can Balance Family and Careers (Oxford University Press, New York, 2007).

[11] M. Ong, Body projects of young women of color in physics: Intersections of gender, race, and science, Soc. Probl. 52, 593 (2005).

[12] B. L. Whitten, S. R. Dorato, M. L. Duncombe, P. E. Allen, C. A. Blaha, H. Z. Butler, K. A. Shaw, B. A. P. Taylor, and B. A. Williams, What works for women in undergraduate physics and what we can learn from women's colleges, J. Women Minorities Sci. Eng. 13, 37 (2007).

[13] B. L. Whitten, S. R. Foster, M. L. Duncombe, P. E. Allen, P. Heron, L. McCullough, K. A. Shaw, B. A. P. Taylor, and H. M. Zorn, What works? Increasing the participation by women in undergraduate physics, J. Women Minorities Sci. Eng. 9, 20 (2003).

[14] B. L. Whitten, S. R. Foster, M. L. Duncombe, P. E. Allen, P. Heron, L. McCullough, K. A. Shaw, B. A. P. Taylor, and H. M. Zorn, "Like a family": What works to create friendly and respectful student-faculty interactions, J. Women Minorities Sci. Eng. 10, 229 (2004).

[15] M. McCormick, R. Barthelemy, and C. Henderson, Women's persistence in undergraduate astronomy: The roles of support, interest, and capital, J. Women Minorities Sci. Eng. 20, 317 (2014).

[16] J. M. Curtin, G. Blake, and C. Cassagnau, The climate for women graduate students in physics, J. Women Minorities Sci. Eng. 3, 95 (1997).
[17] C. Hollenshead, P. Soellner-Younce, and S. A. Wenzel, Women graduate students in mathematics and physics: Reflections on success, J. Women Minorities Sci. Eng. 1, 63 (1994).

[18] R. S. Barthelemy, M. L. Grunert, and C. R. Henderson, The graduate research field choice of women in academic physics and astronomy: A pilot study, in Proceedings of the Physics Education Research Conference (American Institute of Physics, Philadelphia, PA, 2012).

[19] K. P. Dabney and R. H. Tai, Female physicist doctoral experiences, Phys. Rev. ST Phys. Educ. Res. 9, 25 (2013).

[20] A. T. Danielsson, Exploring women university physics students "doing gender" and "doing physics," Gender Educ. 24, 25 (2012).

[21] A. T. Danielsson, Gender in physics education research: A review, in Never Mind the Gap: Gendering Science in Transgressive Encounters, edited by M. Blomqvist and E. Ehnsmyr (University Printers, Uppsala, Sweden, 2010).

[22] A. J. Gonsalves, "Physics and the girly girl-there is a contradiction somewhere": Doctoral students' positioning around discourses of gender and competence in physics, Cultural Study Sci. Educ. 9, 503 (2012).

[23] A. J. Gonsalves, Gender, and doctoral physics education: Are we asking the right questions, in Doctoral Education: Research-Based Strategies for Doctoral Students, Supervisors, and Administrators, edited by L. McAlpine and C. Amundsen (2011).

[24] P. L. Carr et al., Faculty perceptions of gender discrimination and sexual harassment in academic medicine, Ann. Intern. Med. 132, 889 (2000).

[25] L. Nora, M. A. McLaughlin, S. E. Fosson, T. D. Stratton, A. Murphy-Spencer, R.-M. E. Fincher, D. C. German, D. Seiden, and D. B. Witzke, Gender discrimination and sexual harassment in medical education: Perspectives gained by a 14-school study, Acad. Med. 77, 1226 (2002).

[26] K. B. H. Clancy, R. G. Nelson, J. N. Rutherford, and K. Hinde, Survey of academic field experiences (safe): Trainees report harassment and assault, PLoS One 9, 0102172 (2014).

[27] S. Traweek, Beamtimes and Lifetimes (Harvard University Press, Cambridge, MA, 1988).

[28] S. Harding, The Science Question in Feminism (Cornell University Press, Ithaca, London, 1986).

[29] F. Keller, Reflections on Gender and Science (Yale University Press, New Haven, 1985).

[30] C. Wenneras and A. Wold, Nepotism and sexism in peerreview, Nature (London) 387, 341 (1997).

[31] K. L. Milkman, M. Akinola, and D. Chugh, What happens before? A field experiment exploring how pay and representation diferentially shape bias on the pathway into organizations, Soc. Sci. Res. Netw. 100, 1678 (2015).

[32] C. A. Moss-Racusin, J. F. Dovidio, V. L. Brescoll, M. J. Graham, and J. Handelsman, Science faculty's subtle gender biases favor male students, Proc. Natl. Acad. Sci. U.S.A. 109, 16474 (2012).

[33] F. Trix and C. Psenka, Exploring the color of glass: Letters of recommendation for female and male medical faculty, Discourse Soc. 14, 191 (2003). 
[34] R. E. Steinpreis, K. A. Anders, and D. Ritzke, The impact of gender on the review of the curricula vitae of job applicants and tenure candidates: A national empirical study, Sex Roles 41, 509 (1999).

[35] E. A. Klonoff and H. Landrine, The schedule of sexist events: A measure of lifetime and recent sexist discrimination in women's lives, Psychol. Women Q. 19, 439 (1995).

[36] D. W. Sue, Microaggressions and Marginality: Manifestation, Dynamics, and Impact (John Wiley \& Sons, Inc., Hoboken, NJ, 2010).

[37] S. H. Berg, Everyday sexism and posttraumatic stress disorder in women: A correlational study, Violence Against Women 12, 970 (2006).

[38] B. Dardenne, M. Dumont, and T. Bollier, Insifious dangers of benevolent sexism: Consequence for women's performance, J. Pers. Soc. Psychol. 93, 764 (2007).

[39] R. J. Hurst and D. Beesley, Perceived sexism, selfsilencing, and psychological distress in college women, Sex Roles 68, 311 (2013).

[40] H. Landrine, E. A. Klonoff, J. Gibbs, V. Manning, and M. Lund, Physical and psychiatric correlates of gender discrimination: An application of the schedule of sexist events, Psychol. Women Q. 19, 473 (1995).

[41] J. K. Swim, K. M. Eyssell, E. Q. Murdoch, and M. J. Ferguson, Self-silencing to sexism, J. Soc. Issues 66, 493 (2010).

[42] J. K. Swim, L. L. Hyers, L. L. Cohen, and M. J. Ferguson, Everyday sexism: Evidence for its incidence, nature, and psychological impact from three daily diary studies, J. Soc. Issues 57, 31 (2001).

[43] J. M. Grossman and M. V. Proche, Perceived gender and racial/ethnix barriers to stem success, Urban Educ. 49, 698 (2014).
[44] M. Crawford, Transformations: Women, Gender, and Psychology, 2nd ed. (McGraw Hill Companies Inc., New York, NY, 2012).

[45] D. W. Sue, C. M. Capodilupo, G. C. Torino, J. M. Bucceri, A. M. B. Holder, K. L. Nadal, and M. Esquilin, Racial microaggressions in everyday life: Implications for clinical practice, Am. Psychol. 62, 271 (2007).

[46] D. W. Sue and C. M. Capodilupo, Racial, gender, and sexual orientation microaggressions: Implications for counseling and psychotherapy, in Counseling the Culturally Diverse: Theory and Practice, edited by D. W. Sue and D. Sue (John Wiley \& Son, Hoboken, NJ, 2012).

[47] S. N. Hesse-Biber, Handbook of Feminist Research: Theory and Praxis (SAGE Publications, Thousand Oaks, CA, 2007).

[48] S. Harding, Feminist standpoint epistemology, in The Gender, and Science Reader, edited by M. Lederman and I. Bartsch (Routledge, New York, NY, 2001).

[49] K. Charmaz, Constructing Grounded Theory (SAGE, Thousand Oaks, CA, 2006).

[50] J. Des Jardins, The Madame Curie Complex: The Hidden History of Women in Science (Feminist Press, New York, 2010).

[51] V. Valian, Beyond gender schemas: Improving the advancement of women in academia, NWSA Journal 16, 207 (2004).

[52] R. Martell, D. Lane, and C. Emrich, Male-female differences: A computer simulation, Am. Psychol. 51, 157 (1996).

[53] C. J. Blickenstaff, Women and science careers: Leaky pipeline or gender filter?, Gender Educ. 17, 369 (2005). 